\title{
The University of Manchester
}

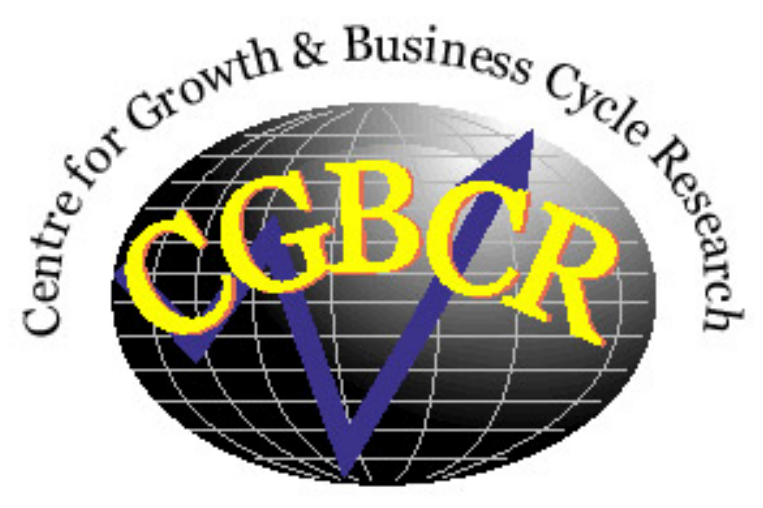

Discussion Paper Series

\section{Distribution and Development in a Model of Misgovernance}

By

Keith Blackburn and Gonzalo F. Forgues-Puccio

Centre for Growth and Business Cycle Research, School of Economic

Studies, University of Manchester, Manchester, M13 9PL, UK

July 2004

Number 042

Download paper from:

http://www.ses.man.ac.uk/cgbcr/discussi.htm

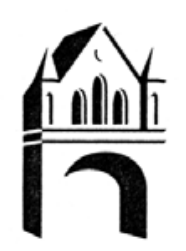




\title{
Distribution and Development in a Model of Misgovernance*
}

\author{
Keith Blackburn and Gonzalo F. Forgues-Puccio \\ Centre for Growth and Business Cycle Research \\ School of Economic Studies, University of Manchester
}

\begin{abstract}
This paper presents an analysis of bureaucratic corruption, income inequality and economic development. The analysis is based on a dynamic general equilibrium model in which bureaucrats are appointed by the government to implement a redistributive programme of taxes and subsidies designed to benefit the poor. Corruption is reflected in bribery and tax evasion as bureaucrats conspire with the rich in providing false information to the government. In accordance with empirical evidence, the model predicts a positive relationship between corruption and inequality and a negative relationship between corruption and development.
\end{abstract}

Keywords: Corruption, inequality, development.

JEL Classification: D31, D73, H26, O11.

${ }^{*}$ Address for correspondence: Keith Blackburn, School of Economic Studies, University of Manchester, Manchester M13 9PL, England. Tel: 0161-275-3908. Fax: 0161275-4928. E-mail: keith.blackburn@man.ac.uk. 


\section{Introduction}

The World Bank has identified corruption - in particular, public sector corruption - as the single greatest obstacle to economic and social development. ${ }^{1}$ Corrupt practices on the part of politicians, civil servants and legislators can distort resource allocations, exacerbate income inequalities and undermine growth prospects. Moreover, such practices can create their own selfsustaining momentum by strengthening the very incentives that give rise to them in the first place. Many countries of the world appear to be plagued by these forces, having seemingly become trapped in a vicious circle of widespread poverty and wholesale misgovernance. To most (if not all) development experts, the fight against corruption is of paramount importance if these countries are to escape from their predicament. In spite of these observations, there exists relatively little theoretical work on the relationship between corruption and development. This is no doubt due to the complex, multi-dimensional nature of this relationship which makes it necessary to consider economic outcomes as reflecting the broader social, political and insitutional environments in which private and public agents operate. Nevertheless, economists are now equipped with the tools and techniques that could be used to meet this challenge, lending rigour and precision to the arguments involved. Our objective in this paper is to make such a contribution. $^{2}$

Generally speaking, public sector corruption refers to illegal, or unauthorised, acts on the part of public officials who abuse their positions of authority to make personal gains. One manifestation of this is bureaucratic corruption, whereby state-appointed bureaucrats exploit their powers of discretion, delegated to them by the government, to further their own interests by indulging in clandestine rent-seeking activities. ${ }^{3}$ Essentially, corruption arises because the government and bureaucracy are involved in a principalagent type relationship from which the latter may gain in a manner that contravenes the interests and rules of the former. Most theoretical work to date has been directed towards understanding the microfoundations of this relationship, using partial equilibrium models to focus on specific questions

\footnotetext{
${ }^{1}$ For an appreciation of the importance of corruption to international policy makers, see the World Bank and IMF web-sites, www.worldbank.org/publicsector/anticorrupt and www.imf.org/external/np/exp/facts/gov.

${ }^{2}$ There are many excellent reviews of the existing literature on corruption and development: see, for example, Bardhan (1997), Jain (2001), Rose-Ackerman (1999) and Tanzi (1998).

${ }^{3}$ Jain (2001) defines other forms of public sector corruption, including political and legislative corruption.
} 
and issues about the nature of corrupt practices and the implications for efficiency and welfare (e.g., Banerjee 1997; Carrillo 2000; Klitgaard 1988, 1990; Rose-Ackerman 1975, 1978, 1999; Shleifer and Vishny 1993). Relatively little research has been undertaken from a macroeconomic perspective with the view to modelling the dynamic general equilibrium interactions between bureaucratic malfeasance and economic development.

Empirical work on corruption has been flourishing over the past few years. This has been due to the construction of several cross-country data sets that are widely regarded as providing reliable measures of corrupt activity. These data sets, or corruption indices, have been compiled by various international organisations (most notably Business International Corporation, Political Risk Services Incorporated and Transparency International) from questionnaire surveys sent to networks of correspondents around the world. There is a strong correlation between these indices which give very similar rankings of countries in terms of the extent to which corruption is perceived to exist. Their publication has led to a rapid accumulation of evidence on the causes and consequences, incidence and importance, of corrupt behaviour within society's public institutions. ${ }^{4}$

One of our concerns in this paper is the relationship between corruption and inequality. In the contemporary literature on income distribution two approaches may be singled out as being especially prominent. The first exemplified in the contributions of Aghion and Bolton (1997), Banerjee and Newman (1993), Blackburn and Bose (2003) and Galor and Zeira (1993) emphasises the role of capital market imperfections in determining the extent to which individuals can borrow and invest, and the extent to which initial inequalities may either vanish or persist over time. The second - instanced in the work of Alesina and Drazen (1991), Alesina and Rodrik (1994), Perotti (1993) and Persson and Tabellini (1994) - stresses the importance of political considerations in influencing redistributive policy, indicating how inequality may affect growth by creating pressures to either implement or postpone different types of public programme. Upto now, the integration of corruption into a theory of income distribution has eluded the attention of most researchers. Yet there are good reasons for believing that corruption has important distributional effects which result in the poor becoming poorer and the rich becoming richer. Two recent examples of this are presented by Ahlin (2001) and Foellmi and Oechslin (2003) who develop occupational choice models in which at least some private agents must bribe public officials in order to engage in entrepreneurial activity that would make them better

\footnotetext{
${ }^{4}$ For more detailed discussions of the indices, see Jain (1998), Tanzi and Davoodi (1997) and Treisman (2000).
} 
off. $^{5}$ Both analyses predict that an increase in the size of bribe payments leads to a redistribution of wealth among the population. In the case of Ahlin (2001) this result arises because those agents who have to pay bribes (agents who lack political influence) are deterred from becoming entrepreneurs and, instead, operate as workers whose wage is lowered by the increase in labour supply to their occupation. ${ }^{6}$ The total value of bribe income (a measure of corruption) displays an inverted u-shaped relationship with inequality. In the case of Foellimi and Oechslin (2003) the result is obtained because those agents with lower initial wealth are less able to put up the required amount of collateral against which they can borrow (due to capital market imperfections) in order to finance the fixed cost of setting up business. ${ }^{7}$ A high incidence of corruption is associated with a polarisation in the income distribution.

In what follows we present an analysis of inequality that focuses on the role of corruptible bureaucrats (as opposed to populist politicians) in determining the scope of redistributive policy (rather than occupational mobility). In principle a government could eliminate inequality without harming growth through an appropriate system of lump-sum transfers and public expenditure programmes administered by a subservient bureaucracy. But even if a government had such an objective and was able to design such a system, its policy could still flounder were bureaucrats not so passive but actively engaged in pursuing their own hidden agenda. Corruption in public policy is often seen as one of the prime causes of persistent inequality. It can lead to both a bias in the tax system in favour of the rich and a deterioration of social programmes designed to benefit the poor. Tax evasion by the wealthy, in collusion with bureaucrats, reduces the tax base and makes the tax system more regressive so that the burden of taxation falls disproportionately on the non-wealthy. Moreover, for any given tax system, tax evasion implies a loss of revenue to the government which may be forced to cut back on its expenditures targeted to the same group of low-income citizens (such as payments of subsidies, spending on health, and funding of education). The provision and quality of social programmes may be threatened even further through the diversion of resources towards other activities that offer greater scope for rent-seeking, or through a more blatant appropriation of public funds in a

\footnotetext{
${ }^{5}$ A third analysis by Glaeser et al. (2002) focuses on the distributional aspects of legislative (as opposed to bureaucratic) corruption. It is shown how inequality may both cause, and be caused by, subversion of legal institutions by the rich and powerful.

${ }^{6}$ The reduction in wages is compounded by a decrease in labour demand resulting from the fewer number of agents who are granted entrepreneurship.

${ }^{7}$ Those agents who do secure loans are more than compensated for the higher bribe payments by a reduction in interest rates associated with a lower demand for credit.
} 
manner that amounts to pure theft. All of these pitfalls have been widely observed in practice. ${ }^{8}$ In short corruption in public policy can manifest in many shapes and forms, all of which are conducive to fostering inequality by compromising the effectiveness of programmes designed to alleviate poverty. Our analysis aims to provide a simple illustration of this.

Another of our concerns is the relationship between corruption and growth. Early research suggested that corruption might actually be growth-enhancing by helping to circumvent institutional hurdles (red tape) in the bureaucratic process: that is, bribes may act as "speed money" which bureaucrats accept in return for by-passing cumbersome regulations that work against efficiency (e.g., Huntington 1968; Leff 1964; Leys 1970). ${ }^{9}$ This view may be challenged on both conceptual and empirical grounds, and the prevailing wisdom is that corruption is detrimental to growth due to its adverse effects on resource allocations through the distortion of incentives and market signals. ${ }^{10}$ As above, however, there exists only a small body of theoretical work that formalises the arguments involved. Recent examples include the contributions of Ehrlich and Lui (1999) and Sarte (2000). The former develop a model in which opportunities to profit from bureaucratic malpractice create incentives for individuals to compete for the privelage of holding public office. These incentives lead to a diversion of resources away from growthpromoting activities (investments in human capital) towards power-seeking activities (investments in political capital). The latter constructs a framework in which rent-seeking bureaucrats restrict the entry of firms into the formal sector of the economy which has a better system of property rights and law enforcement than the informal sector. When the costs of informality are high, growth is reduced relative to the free-entry case.

\footnotetext{
${ }^{8}$ The single most extensive source of evidence is the World Bank's web-site, referred to in footnote 1 .

${ }^{9}$ More recent expositions of efficiency-enhancing corruption can be found in Lui (1985) and Acemoglou and Verdier (1998). The former suggests that bribes may form part of a Nash equilibrium strategy in a non-cooperative game, where inefficiency in public administration is reduced by the minimisation of waiting costs. The latter suggest that some degree of corruption may be part of an optimal allocation in the presence of incomplete contracts since public officials, though corrupt, can help in the enforcement of property rights. A similar idea is expressed in Acemoglou and Verdier (2000) who argue more generally that corruption may be the necessary price to pay for correcting market failures.

${ }^{10}$ Conceptually, there are two main arguments against the "speed money" hypothesis: first, although bribery may speed up individual transactions with bureaucrats, both the sizes of bribes and the number of transactions may increase so as to produce an overall net loss in efficiency; second, and more fundamentally, the distortions that bribes are meant to mitigate are often the result of corrupt practices to begin with and should therefore be treated as endogenous, rather than exogenous, to the bureaucratic process. Empirically, the hypothesis is refuted by a large body of evidence, alluded to below.
} 
The above analyses are successful in explaining how corruption may impact on growth without delving too deeply into questions as to why corruption might arise in the first place and why corruption might either persist or decline over time. These questions are important, especially given the wide diversity of corruption levels across countries. There is a strong presumption that the quality of governance not only influences, but is also influenced by, the level of economic prosperity. The challenge for theorists is to explain this two-way causality through an account of the joint, endogenous determination of corruption and development within the context of a single, unifying framework. Our analysis intends to provide such an account.

The model that we use describes an artificial economy in which private agents, or households, are divided into different income classes. Public agents, or bureaucrats, are charged with the responsibility for administering government policy. Specifically, bureaucrats are authorised to collect taxes and disburse subsidies in their execution of a redistributive programme designed to benefit the poor. ${ }^{11}$ This authority allows bureaucrats to engage in corrupt practices that are difficult to monitor by the government. In particular, bureaucrats may conspire with wealthy households in bribery and tax evasion: a bribe to a bureaucrat holds the promise that the income of a household will be reported falsely and exempt from any tax. ${ }^{12}$ It is costly for a bureaucrat to behave in this way and it is costly for the government to detect such behaviour. This framework incorporates the essential features that state intervention entails a delegation of powers to public officials, that these powers may be abused in rent-seeking activities and that these activities impose costs on society. Against this background, we show that inequality is higher, while growth is lower, in a corrupt environment than in a non-corrupt environment. The precise effects of corruption are to reduce the level of subsidies (making all of the poor worse off), to enable scope for tax evasion (making some of the rich better off), and to depress aggregate savings (impeding the process of capital accumulation). In addition, we establish reverse causation: whether or not corruption occurs depends

\footnotetext{
${ }^{11}$ We abstract from other instruments of public policy that may be used in poverty alleviation, such as public goods and services. In our concluding remarks we indicate how the model may be extended to incorporate these aspects (which would tend to strengthen our results).

${ }^{12}$ This type of collusion between tax payers and tax officials forms the basis of several microeconomic models of tax evasion (e.g., Besley and McLaren 1993; Chander and Wilde, 1992; Mookherjee and Png 1995). Arguably, corruption is most difficult to detect - and therefore most pervasive - when individuals act collusively in anticipation of mutual benefits that deter protest and dissent. This may be contrasted to the case of non-collusive corruption, whereby one individual may stand to gain at the expense of another who may then be inclined to report the offense.
} 
on the level of economic activity. More precisely, there is a critical level of capital below which corruption takes place and above which corruption is absent. This gives rise to mutliple development regimes associated with different incidences of corruption and different levels of inequality. Depending on parameter values and initial conditions, transition between these regimes may or may not be feasible. In the absence of transition, there are multiple long-run equilibria, including a poverty trap equilibrium in which corruption and inequality remain permanently high. These properties of the model allow us to explain why the extent of corruption, inequality and poverty appear to vary so markedly and persistently around the world. ${ }^{13}$

The implications of our analysis are consistent with recent empirical evidence acquired from econometric investigations using various cross-country data sets. Several studies have identified a strong positive correlation between the incidence of corruption and the degree of income inequality. GyimahBrempong (2003), using a panel of African countries, estimates sizeable increases in the Gini coefficient as the level of corruption increases. The same finding appears in the contributions of Gupta et al. (2002) and Li et al. (2000), each of which is based on a broader sample of both developed and developing countries. In the case of the latter, it is also found that corruption accounts for a substantial proportion of the Gini differential between the poor and rich regions of the world. Foellmi and Oechslin (2003) present additional results which suggest that an increase in the level of corruption leads to an increase in the income share of the wealthiest members of the population. Equally convincing is the empirical testimony of a strong negative relationship between corruption and development. A number of authors - including Gyimah-Brempong (2003), Li et al. (2000), Mauro (1995) and the United Nations (1989) - conclude that corruption has a significantly adverse effect on growth. These and other studies also provide evidence on various ways in which corruption might take hold, such as lowering rates of investment (e.g., Mauro 1995), creating obstacles to doing business (e.g., World Bank 2002),

\footnotetext{
${ }^{13}$ More traditional explanations appeal to cross-country differences in institutions, regulations and social customs that influence opportunities for engaging in corrupt practices and that shape public attitudes towards these practices. Such arguments have been criticised for being almost tautological and for failing to account for real-world observations (e.g., Bardhan 1997). Another explanation, grounded more firmly on economic principles, is based on the notion of frequency-dependent equilibria, according to which corruption at the group level is a key determinant of corruption at the individual level (e.g., Andvig and Moene 1990; Cadot 1987). This account may be questioned for leaving too much to chance: whether or not corruption occurs depends primarily on whether or not it is expected to occur. Our own analysis is rather more informative in the sense that it reveals how the limiting outcome of the economy depends predictably on fundamentals (preferences and technologies).
} 
reducing inflows of foreign investment (e.g., Wei 2000) and causing misallocations of public expenditures (e.g., Mauro 1997; Tanzi and Davoodi 1997). The notion that causality may run in the opposite direction is evidenced in Treisman (2000) who reports that a significant proportion of the variations in corruption indices can be explained by variations in per-capita income levels. In addition, the idea that corruption and poverty may co-exist as persistent, rather than transient, phenomena, is suggested by the casual observation that many of the most poor and corrupt countries of the past are among the most poor and corrupt countries of today (e.g., Bardhan 1997). Finally, we note the empirical finding that, as predicted by our analysis, incomes appear to be more equally distributed in wealthier economies (e.g., Ravallion and Chen 1997; World Bank 1990, 1991).

The remainder of the paper is organised as follows. In Section 2 we describe the set-up of the economy. In Section 3 we identify conditions under which corruption occurs. In Section 4 we address the issue of corruption and inequality. In Section 5 we turn to the study of corruption and development. In Section 6 we make a few a concluding remarks.

\section{The Environment}

Time is discrete and indexed by $t=0, . ., \infty$. There is a constant population of two-period-lived agents belonging to overlapping generations of dynastic families. Agents of each generation are divided into two groups of citizens private individuals (or households), of whom there is a fixed measure of mass $M$, and public servants (or bureaucrats), of whom there is a fixed measure of mass $N<M{ }^{14}$ Households work for firms in the production of output, while bureaucrats work for the government in the administration of fiscal policy. Households are differentiated according to differences in their incomes which imply differences in their propensities to be taxed or subsidised. Bureaucrats are differentiated according to differences in their proclivities towards rentseeking. ${ }^{15}$ Corruption arises from the incentive of a (corruptible) bureaucrat to conspire with a (taxable) household in concealing information (the household's income) from the government. In doing this, the bureaucrat expects to gain from his acceptance of a bribe, while the household expects to gain

\footnotetext{
${ }^{14} \mathrm{We}$ assume that agents are differentiated at birth according to their abilities and skills. A population of $M$ agents lack the skills necessary to become bureaucrats, while a population of $N$ agents posess these skills. The latter are induced to become bureaucrats by an allocation of talent condition established below.

${ }^{15}$ Such differences may reflect differences in proficiencies at being corrupt or differences in moral attitudes towards being corrupt (e.g., Acemoglou and Verdier 2000).
} 
from its evasion of tax. All agents are risk neutral, working (and saving) only when young and consuming only when old. Firms, of which there is a unit mass, hire labour from households and rent capital from all agents in perfectly competitive markets.

\subsection{The Government}

We assume that the government redistributes wealth from the rich to the poor by means of taxes and subsidies. The tax on each rich (high-income) household is denoted by $\tau_{t}$, and the subsidy to each poor (low-income) household is denoted by $\sigma_{t}$. Responsibility for the collection of taxes and disbursement of subsidies lies with bureaucrats using the authority delegated to them by the government. For simplicity, we assume that bureaucrats are neither liable to pay taxes nor eligible to receive subsidies. The government sets the salaries of bureaucrats in accordance with the following considerations. Any bureaucrat (whether corruptible or non-corruptible) can work for a firm to receive an income equal to the wage paid to households. Any bureaucrat who is willing to accept a salary less than this wage must be expecting to receive compensation through bribery and is therefore immediately identified as being corrupt. As in other analyses (e.g., Acemoglou and Verdier 1998), we assume that a bureaucrat who is discovered to be corrupt is subject to the maximum fine of having all of his income confiscated. Given this, then no corruptible bureaucrat would ever reveal himself in the way described above. As such, the government can minimise its labour costs, while ensuring complete bureaucratic participation, by setting the salaries of all bureaucrats equal to the wage paid by firms to households. ${ }^{16}$

Since the government knows how much tax revenue is due in the absence of corruption (since it knows the number of taxable households and since it is responsible for setting taxes), any shortfall of revenue below this amount reveals that corruption is occurring. Under such circumstances, the government investigates the behaviour of bureaucrats using a costly and imprecise monitoring technology. This technology entails $e$ units of additional expenditure and implies that a bureaucrat who is corrupt faces a probability, $p \in(0,1)$, of avoiding detection, and a probability, $1-p$, of being found out. The tax-evading household with whom the bureaucrat conspires faces the same probabilities of remaining anonymous and being exposed. In the event of the latter, the household is forced to pay its full tax liability.

\footnotetext{
${ }^{16}$ This has the same interpretation as the allocation of talent condition in Acemoglou and Verdier (2000). The government cannot force any of the $N$ potential bureaucrats to actually take up public office, but it is able to induce all of them to do so by paying what they would earn elsewhere.
} 
The government runs a continuously balanced budget by equating its total revenues to its total expenditures. From above, the former consist of the taxes paid by high-income households plus the fines paid by any bureaucrats who are caught being corrupt, while the latter include the salaries of bureaucrats and the costs of monitoring in the event of corruption. For given values of these items, the level of subsidies is determined residually so as to ensure that the government's budget constraint is satisfied.

\subsection{Households}

The population of households is distributed across three income classes. There is a fraction, $\mu_{l} \in(0,1)$, of low-income (l-type) households, a fraction, $\mu_{m} \in(0,1)$, of middle-income ( $m$-type) households and a remaining fraction, $\mu_{h}=1-\mu_{l}-\mu_{m}$, of high-income ( $h$-type) households. Each household is endowed with one unit of labour which it supplies inelastically to firms in return for a wage. Differences in wages reflect differences in skills, expertise and other attributes of human capital with which households are born. For the sake of generality, we also assume that each household receives some additional fixed amount of income which differentiates it further from others. This extra income is inessential to our analysis, as is its precise origins. Thus, rather than being specific and adding unnecessary detail to the model, we prefer to leave this term general and establish our results within a broader, more inclusive, context. ${ }^{17}$ A household is wealthier than another because both its variable and fixed incomes are higher. Specifically, a household of income class $i(=l, m, h)$ recieves wage earnings of $w_{i t}$ and non-wage earnings of $q_{i}$, where $w_{l t}<w_{m t}<w_{h t}$ and $q_{l}<q_{m}<q_{h}$. Only low-income households are eligible to receive subsidies and only high-income households are liable to pay taxes, where the official amount of tax that must be paid is determined by the linear tax rule $\tau_{t}=\tau_{0}+\tau_{1} w_{h t}$. The total final income (or savings) of each type of household is denoted by $s_{i t}$. For the purposes of the present analysis, we assume that the identity of a low-income household is public knowledge, but that the identity of a middle- or high-income household is private information. This assumption is sufficient to admit the

\footnotetext{
${ }^{17}$ One may think of this income as an inheritance, the size of which depends on the utility derived by parents from leaving bequests. If the marginal rate of substitution between consumption and bequests is independent of the level of consumption, then the optimal size of bequest will be constant. Alternatively, one may think of differently-skilled agents as being able to earn different amounts of fixed income from working overtime or from working in some other occupation (e.g., home production). Finally, one may consider this fixed income as being part of normal wage earnings if firms are able to produce at least some amount of output using labour alone.
} 
possibility of corruption, whilst also serving to simplify the analysis by limiting the scope for corrupt behaviour. In particular, it allows corruption to occur in the evasion of taxes, but not in the appropriation of subsidies. Thus, by bribing a bureaucrat, a high-income household may seek to evade taxes by having itself reported to the government as a middle-income type. It cannot, however, seek to enrich itself further by laying claim to a subsidy through its misrepresentation as a low-income type (and neither can a middle-income household do this). ${ }^{18}$

Given the above, we may compute the total income, or wealth, of each type of household as follows. For a low-income type, total wealth is equal to the value of own income, $w_{l t}+q_{l}$, plus the value of subsidies, $\sigma_{t}$. For a middle-income type, total wealth is equal to just the value of own income, $w_{m t}+q_{m}$. For a high-income type, wealth status is more a matter of choice, being determined by the household's decision as to whether or not to conspire with a bureaucrat in bribery and tax evasion. If not, then final wealth is equal to the value of own income, $w_{h t}+q_{h}$, less the value of taxes, $\tau_{0}+\tau_{1} w_{h t}$. If so, then final wealth is uncertain and depends on the amount of bribe paid and the probability of being caught. Let $b_{t}$ denote the bribe. With probability $p$, the household and bureaucrat succeed in their conspiracy, implying that the household obtains $w_{h t}+q_{h}$, less $b_{t}$. With probability $1-p$, their collusion is exposed, meaning that the household retains the same amount, less $\tau_{0}+$ $\tau_{1} w_{h t}$. In conclusion, we may summarise the profile of household incomes as

$$
\begin{gathered}
s_{l t}=w_{l t}+\sigma_{t}+q_{l}, \\
s_{m t}=w_{m t}+q_{m}, \\
s_{h t}=\left\{\begin{array}{l}
\left(1-\tau_{1}\right) w_{h t}-\tau_{0}+q_{h} \text { if } b_{t}=0 \\
w_{h t}-b_{t}+q_{h} \text { with prob. } p \text { if } b_{t}>0, \\
\left(1-\tau_{1}\right) w_{h t}-\tau_{0}-b_{t}+q_{h} \text { with prob. } 1-p \text { if } b_{t}>0 .
\end{array}\right.
\end{gathered}
$$

Throughout our analysis, we assume appropriate restrictions on parameter values to preclude the possibility of a household changing income class purely as a result of redistributive policy.

\footnotetext{
${ }^{18}$ Allowing for such a possibility would tend to strengthen our results by increasing the scope for corrupt behaviour. The same would be true if bureaucrats could capture rents by demanding bribes from low-income households in return for subsidies. Again, this does not arise in our model because the government knows the identities of these households and the incomes to which they are entitled: any bureaucrat who was to make such a demand could simply be reported to the government, leading to his immediate apprehension and prosecution.
} 


\subsection{Bureaucrats}

The population of bureaucrats is divided into a fraction, $\nu_{c} \in(0,1)$, of unknown corruptible (c-type) bureaucrats and a remaining fraction, $\nu_{n}=1-\nu_{c}$ of unknown non-corruptible ( $n$-type) bureaucrats. By definition, the former are susceptible to bribery, while the latter are not. Each bureaucrat is endowed with one unit of labour which he supplies inelastically to the government in return for a salary. As indicated earlier, this salary is set equal to the wage that the bureaucrat could earn from supplying his labour to firms, instead. For simplicity, we assume that the productivity of a bureaucrat in this alternative occupation is the same as that of a middle-income household, in which case the bureaucrat receives a salary of $w_{m t} .{ }^{19}$ For further convenience, we assume that a bureaucrat has no other earnings. The total final income of a bureaucrat is denoted by $s_{j t}(j=c, n)$. As an administrator of the government's policy of redistribution, each bureaucrat has jurisdiction over $\frac{\mu_{h} M}{N}$ high-income households, from which he collects taxes, and $\frac{\mu_{l} M}{N}$ low-income households, to which he gives subsidies.

The total incomes of bureaucrats are deduced as follows. For a noncorruptible bureaucrat, total income is simply equal to earnings from labour, $w_{m t}$. For a corruptible bureaucrat, total income is determined according to whether or not corruption is engaged in. If not, then the bureaucrat receives just his labour earnings, $w_{m t}$, as before. If so, then the bureaucrat's final wealth depends on the amount of bribes received, the chances of being caught, the resources spent on trying to avoid detection and the penalties incurred if rent-seeking is exposed. In general, corrupt individuals, in order to remain inconspicuous, may hide their illegal income, may invest this income differently from legal income and may alter their patterns of expenditure. These activities typically entail costs in one form or another. For the purposes of the present analysis, we make the simple assumption that a bureaucrat who is corrupt needs to spend resources on trying to conceal his behaviour if he is to stand any chance of not being caught. It is plausible to imagine that more resources must be spent to conceal more illegal income. We model this in terms of a convex cost function, $\beta\left(B_{t}\right)$, where $B_{t}=\left(\frac{\mu_{h} M}{N}\right) b_{t}$ is the total value of bribes that the bureaucrat receives. With probability $p$, the bureaucrat succeeds in his deception and retains the net value of his salary and rents, $w_{m t}+B_{t}-\beta\left(B_{t}\right)$. With probability $1-p$, the bureaucrat is apprehended and left with nothing. It follows that the income profile of bureaucrats may

\footnotetext{
${ }^{19}$ This assumption serves to save on notation and may be used to justify the exemption of bureaucrats from receiving any subsidies and paying any taxes by placing them in the same position as middle-income households.
} 
be summarised as

$$
\begin{gathered}
s_{n t}=w_{m t} \\
s_{c t}=\left\{\begin{array}{l}
w_{m t} \text { if } b_{t}=0 \\
w_{m t}+B_{t}-\beta\left(B_{t}\right) \text { with prob. } p \text { if } b_{t}>0 \\
0 \text { with prob. } 1-p \text { if } b_{t}>0
\end{array}\right.
\end{gathered}
$$

\subsection{Firms}

The representative firm combines $x_{i t}$ units of type- $i(=l, m, h)$ labour with $k_{t}$ units of homogeneous capital to produce $y_{t}$ units of output according to

$$
y_{t}=A\left(a_{l} x_{l t}^{\alpha}+a_{m} x_{m t}^{\alpha}+a_{h} x_{h t}^{\alpha}\right) k_{t}^{1-\alpha} K_{t}^{\alpha},
$$

$\left(A>0,0<a_{l}<a_{m}<a_{h}, \alpha \in(0,1)\right)$ where $K_{t}$ denotes the aggregate stock of capital. ${ }^{20}$ The distinction between different types of labour corresponds to the division of households into low-skilled, medium-skilled and high-skilled workers, and is reflected in the different productivity parameters $a_{l}, a_{m}$ and $a_{h}$. The firm hires labour from low-skilled households at the wage rate $w_{l t}$, from medium-skilled households at the wage rate $w_{m t}$ and from high-skilled households at the wage rate $w_{h t}$. Capital is rented from all agents at the rental rate $r_{t}$. Profit maximisation implies $w_{i t}=A \alpha a_{i} x_{i t}^{\alpha-1} k_{t}^{1-\alpha} K_{t}^{\alpha}$ and $r_{t}=$ $A(1-\alpha)\left(a_{l} x_{l t}^{\alpha}+a_{m} x_{m t}^{\alpha}+a_{h} x_{h t}^{\alpha}\right) k_{t}^{-\alpha} K_{t}^{\alpha}$. Since $x_{i t}=\mu_{i} M$ and $k_{t}=K_{t}$ in equilibrium, we may write these conditions as

$$
\begin{gathered}
w_{i t}=A \alpha a_{i}\left(\mu_{i} M\right)^{\alpha-1} k_{t}, \\
r_{t}=r=A(1-\alpha) a,
\end{gathered}
$$

where $a=a_{l}\left(\mu_{l} M\right)^{\alpha}+a_{m}\left(\mu_{m} M\right)^{\alpha}+a_{h}\left(\mu_{h} M\right)^{\alpha}$. Thus equilibrium wages are proportional to the capital stock, while the equilibrium interest rate is constant. The parameter restriction $a_{l} \mu_{l}^{\alpha-1}<a_{m} \mu_{m}^{\alpha-1}<a_{h} \mu_{h}^{\alpha-1}$ ensures that $w_{l t}<w_{m t}<w_{h t}$.

\section{The Incentive to be Corrupt}

Corruption occurs if a high-income household and a corruptible bureaucrat find it mutually advantageous (or non-disadvantangeous) to conspire with

${ }^{20}$ This aggregate externality - a common feature of endogenous growth models - allows us to work with a simple $A K$ technology, where the social returns to capital are constant. Our results would be unchanged were we to assume diminishing returns to capital instead. 
each other in concealing information from the government. Under such circumstances, there is bribery and tax evasion. In what follows we study the individual incentives of private and public agents to behave in this way.

For a corruptible bureaucrat, the expected return from accepting a bribe is deduced from (5) as $E\left(s_{c t} \mid b_{t}>0\right)=p\left[w_{m t}+B_{t}-\beta\left(B_{t}\right)\right]$. This return is maximised by setting $\beta^{\prime}(\cdot)=1$, implying an optimal fixed amount of bribe income, $B_{t}=B^{*}$, and a corresponding optimal fixed size of bribe, $b_{t}=b^{*}$, for all $t$. The bureaucrat's expected return from not accepting a bribe is also obtained from (5) as $E\left(s_{c t} \mid b_{t}=0\right)=w_{m t}$. If $E\left(s_{c t} \mid b_{t}>0\right) \geq E\left(s_{c t} \mid b_{t}=0\right)$, then the bureaucrat has an incentive to be corrupt. For the case in which $b_{t}=b^{*}$, this condition may be stated as

$$
p\left[B^{*}-\beta\left(B^{*}\right)\right] \geq(1-p) w_{m t} .
$$

Intuitively, a bureaucrat is more likely to be corrupt the less he expects to lose in legal income if he is caught.

For a high-income household, the expected returns from paying and not paying a bribe are computed from $(3)$ as $E\left(s_{h t} \mid b_{t}>0\right)=\left[1-(1-p) \tau_{1}\right] w_{h t}-$ $(1-p) \tau_{0}-b_{t}+q_{h}$ and $E\left(s_{h t} \mid b_{t}=0\right)=\left(1-\tau_{1}\right) w_{h t}-\tau_{0}+q_{h}$, respectively. The household has an incentive to offer a bribe if $E\left(s_{h t} \mid b_{t}>0\right) \geq E\left(s_{h t} \mid b_{t}=0\right)$. This condition may be written as

$$
b_{t} \leq p\left(\tau_{1} w_{h t}+\tau_{0}\right) .
$$

Intuitively, the household is prepared to bribe a bureaucrat by no more than what it expects to save in taxes.

Observe that, if (10) is satisfied for $b_{t}=b^{*}$, then the household is willing to pay the bureaucrat his optimal bribe. Moreover, if $b^{*} \leq p \tau_{0}$, then the household is always willing to do this. For the purposes of simplifying our subsequent analysis, we assume that this is the case. Under such circumstances, the condition for corruption to occur is given solely by the condition in (9), being determined exclusively by the incentives of corruptible bureaucrats. $^{21}$

\section{Corruption and Inequality}

The distribution of income in the economy is determined by the system of taxes and subsidies used to transfer resources from high-income households

\footnotetext{
${ }^{21}$ Evidently, our analysis implies that either all or none of these bureaucrats will be corrupt. This is a simplification of little consequence to our main results. In our concluding remarks, we indicate how the model could be extended to allow for smooth variations in the incidence of corruption
} 
to low-income households. This system is administered by bureaucrats using the authority delegated to them by the government. As shown above, some of these public officials may be tempted to abuse their authoritative powers by colluding with potential tax payers in the concealment and fabrication of information. Our objective below is to demonstrate how such behaviour can undermine the effectiveness of public policy in redistributing wealth and reducing inequality.

Consider, first, the case in which corruption is absent, meaning that the condition in (9) is violated. Each and every bureaucrat, of whom there are $N$, collects the maximum amount of tax revenue, $\left(\frac{\mu_{h} M}{N}\right)\left(\tau_{1} w_{h t}+\tau_{0}\right)$, from those high-income households under his jurisdiction and returns all of this revenue to the government. The total proceeds from taxation are used by the government to finance its total expenditures on the salaries of bureaucrats, $N w_{m t}$, and subsidies to low-income households, $\mu_{l} M \sigma_{t}$. The amount of subsidy that each of these households receives, denoted $\widehat{\sigma}_{t}$, is determined from the government's budget constraint as

$$
\mu_{l} M \widehat{\sigma}_{t}=\mu_{h} M\left(\tau_{1} w_{h t}+\tau_{0}\right)-N w_{m t}
$$

where we we assume that $\mu_{h} M \tau_{1} w_{h t}-N w_{m t}>0 .^{22}$ Given (11), the final incomes of households are established from (1), (2) and (3) (excluding the case in which bribe payments are positive). Let $\widehat{\pi}\left(s_{t}\right)$ denote the population of households with an income of $s_{t}$. Then the distribution of household income in this non-corrupt environment is summarised by

$$
\widehat{\pi}(\cdot)=\left\{\begin{array}{l}
\mu_{l} M \text { for } s_{t}=w_{l t}+\widehat{\sigma}_{t}+q_{l} \equiv \widehat{s}_{l t} \\
\mu_{m} M \text { for } s_{t}=w_{m t}+q_{m} \equiv \widehat{s}_{m t} \\
\mu_{h} M \text { for } s_{t}=\left(1-\tau_{1}\right) w_{h t}-\tau_{0}+q_{h} \equiv \widehat{s}_{h t} .
\end{array}\right.
$$

Now consider the case in which corruption exists as a result of the condition in (9) being satisified. The total population of corrupt bureaucrats is $\nu_{c} N$, of whom a fraction, $p$, evade detection by the government, while the remaining fraction, $1-p$, are caught. The government's tax receipts are zero from each of the former and $\left(\frac{\mu_{h} M}{N}\right)\left(\tau_{1} w_{h t}+\tau_{0}\right)$ from each of the latter who is also fined the amount $w_{m t}+B^{*}-\beta\left(B^{*}\right)$. From each non-corrupt bureaucrat, of whom there are $\nu_{n} N$, the government receives $\left(\frac{\mu_{h} M}{N}\right)\left(\tau_{1} w_{h t}+\tau_{0}\right)$ in tax revenue. In addition to its outlays on bureaucrats' salaries, $N w_{m t}$, and subsidies, $\mu_{l} M \sigma_{t}$, the government devotes $e$ units of expenditure to monitoring.

${ }^{22}$ This condition merely ensures that subsidies are never decreasing and therefore never negative (i.e., $\widehat{\sigma}_{t}>0$ for all $t$ ). By virtue of (7), we may re-state the condition as the parameter restriction $\mu_{h} M \tau_{1} a_{h} \mu_{h}^{\alpha-1}>N a_{m} \mu_{m}^{\alpha-1}$. 
As above, the amount of subsidy paid to each low-income household, denoted $\widetilde{\sigma}_{t}$, may be computed from the government's budget constraint as

$$
\begin{aligned}
\mu_{l} M \widetilde{\sigma}_{t}= & \left(1-p \nu_{c}\right) \mu_{h} M\left(\tau_{1} w_{h t}+\tau_{0}\right)-\left[1-(1-p) \nu_{c}\right] N w_{m t} \\
& +(1-p) \nu_{c} N\left[B^{*}-\beta\left(B^{*}\right)\right]-e
\end{aligned}
$$

where we similarly assume that $\left(1-p \nu_{c}\right) \mu_{h} M \tau_{1} w_{h t}>\left[1-(1-p) \nu_{c}\right] N w_{m t}{ }^{23}$ Given (13), the final incomes of households are deduced from (1), (2) and (3) (including the case in which bribe payments are positive). Conitnuing as before, denote by $\tilde{\pi}\left(s_{t}\right)$ the population of households with an income of $s_{t}$. Note that the fraction of high-income households that pay (do not pay) bribes is equal to $v_{c}\left(\nu_{n}\right)$, the fraction of bureacrats who are corrupt (noncorrupt). Note also that a proportion, $p(1-p)$, of bribe-paying households succeed (fail) in their attempts to evade taxes. It follows that the distribution of household income in this corrupt environment is given by

$$
\widetilde{\pi}(\cdot)=\left\{\begin{array}{l}
\mu_{l} M \text { for } s_{t}=w_{l t}+\widetilde{\sigma}_{t}+q_{l} \equiv \widetilde{s}_{l t} \\
\mu_{m} M \text { for } s_{t}=w_{m t}+q_{m} \equiv \widetilde{s}_{m t}, \\
\nu_{n} \mu_{h} M \text { for } s_{t}=\left(1-\tau_{1}\right) w_{h t}-\tau_{0}+q_{h} \equiv \widetilde{s}_{h t}^{1}, \\
p \nu_{c} \mu_{h} M \text { for } s_{t}=w_{h t}-b^{*}+q_{h} \equiv \widetilde{s}_{h t}^{2} \\
(1-p) \nu_{c} \mu_{h} M \text { for } s_{t}=\left(1-\tau_{1}\right) w_{h t}-\tau_{0}-b^{*}+q_{h} \equiv \widetilde{s}_{h t}^{3} .
\end{array}\right.
$$

A comparison of (11) and (13) reveals that

$$
\begin{aligned}
\mu_{l} M \widetilde{\sigma}_{t}= & \mu_{l} M \widehat{\sigma}_{t}-\nu_{c} \mu_{h} M\left[p\left(\tau_{1} w_{h t}+\tau_{0}\right)-b^{*}\right] \\
& -\nu_{c} N\left\{p\left[B^{*}-\beta\left(B^{*}\right)\right]-(1-p) w_{m t}\right\}-\nu_{c} N \beta\left(B^{*}\right)-e
\end{aligned}
$$

Recall that, in the case of corruption, both of the conditions in (9) and (10) are satisfied. Consequently, the above expression yields the unambiguous result that $\widetilde{\sigma}_{t}<\widehat{\sigma}_{t}$ : that is, for any given wage, the amount of subsidy received by each low-income household is lower under corruption than under non-corruption. This follows from the fact that corruption entails both a loss of revenue to the government from the evasion of taxes by high-income households and an additional outlay for the government from the costly monitoring of bureaucratic behaviour. Although the government earns some extra revenue from fines, the net effect of bureaucratic malfeasance is to reduce the amount of resources available for subsidies.

\footnotetext{
${ }^{23}$ As before, this condition ensures that subsidies are never decreasing. Using (7), it may be re-written as the parameter restriction $\left(1-p \nu_{c}\right) \mu_{h} M \tau_{1} a_{h} \mu_{h}^{\alpha-1}>[1-(1-$ p) $\left.\nu_{c}\right] N a_{m} \mu_{m}^{\alpha-1}$. If $p \nu_{c}<\frac{1}{2}$, then the condition is automatically satisfied, given our previous assumption that $\mu_{h} M \tau_{1} a_{h} \mu_{h}^{\alpha-1}>N a_{m} \mu_{m}^{\alpha-1}$. If $p \nu_{c}>\frac{1}{2}$, then the reverse is true. Together with other parameter restrictions, we can then ensure that subsidies are always positive $\left(\widetilde{\sigma}_{t}>0\right.$ for all $\left.t\right)$.
} 
Given the above, we may deduce precisely how corruption affects the distribution of income as follows. Naturally, corruption has no bearing on the wealth status of middle-income households $\left(\widetilde{s}_{m t}=\widehat{s}_{m t}\right)$, of which there is a total mass of $\mu_{m} M$. By contrast, all low-income households, the mass of which is $\mu_{l} M$, are made worse off by corruption $\left(\widetilde{s}_{l t}<\widehat{s}_{l t}\right)$ due to the lower level of subsidies $\left(\widetilde{\sigma}_{t}<\widehat{\sigma}_{t}\right)$. As regards the wealth status of high-income households, the consequences of corruption are more varied: there is a mass of these households, $\nu_{n} \mu_{h} M$, that deal with non-corruptible bureaucrats and that are unaffected by corruption $\left(\widetilde{s}_{h t}^{1}=\widehat{s}_{h t}\right)$; there is another mass of these households, $p \nu_{c} \mu_{h} M$, that deal with corruptible bureaucrats and that are made better off $\left(\widetilde{s}_{h t}^{2}>\widehat{s}_{h t}\right)$ by succeeding in their attempts to evade taxes; and there is a remaining mass of these households, $(1-p) \nu_{c} \mu_{h} M$, that also deal with corruptible bureaucrats but that are made worse off $\left(\widetilde{s}_{h t}^{3}<\widehat{s}_{h t}\right)$ by failing in their attempts to evade taxes. Based on these observations, we present Figure 1 as an illustration of how the distribution of income in a non-corrupt environment compares with the distribution of income in a corrupt environment. Evidently, the latter displays greater variation than the former. In particular, by making all low-income households worse off and some high-income households better off, corruption stretches out the distribution in both directions so as to widen the gap between the rich and poor. In short, corruption impedes the functioning of redistributive policy and, in doing so, increases the degree of income inequality. ${ }^{24}$

\section{Corruption and Development}

The foregoing analysis presents a snapshot of events at any point in time under one of two possible scenarios - the case in which all corruptible bureaucrats are corrupt and the case in which no corruptible bureaucrat is corrupt. Whichever of these scenarios transpires is governed by the condition in (9). For any given level of wages, $w_{m t}$, an economy in which this condition is satisfied will display greater income inequality than an economy in which the condition is violated. In what follows, we present a similar analysis that focuses on the effects of corruption on capital accumulation and growth. In addition, we demonstrate how corruption, itself, is influenced by the level of

\footnotetext{
${ }^{24}$ Our discussion has been concerned with the income distribution of only households. The income distribution of bureaucrats is also made more unequal by corruption. Only non-corrupt bureaucrats earn the same amount of income $\left(w_{m t}\right)$ as all bureaucrats earn in the absence of corruption. Of the population of corrupt bureaucrats, there are some who earn more income $\left(w_{m t}+B^{*}-\beta\left(B^{*}\right)\right)$ and others who earn less income (zero) by accepting bribes.
} 
economic activity, or level of economic development. This arises from the fact that wages are not exogenous nor fixed in our model. On the contrary, they are determined endogenously with other economic outcomes along the dynamic path of capital accumulation. Accordingly, corruption and development are linked together in a relationship that is fundamentally two-way causal.

The path of capital accumulation is determined using the equilibrium condition that the total demand for capital by firms is equal to the total savings of all agents. The total value of savings in the absence and presence of corruption is computed straightforwardly from the income (savings) distributions in (12) and (14), respectively. After substituting for wages using (7), together with subsidies using (11) and (13), we find that capital accumulation in a non-corrupt environment is described by

$$
\widehat{k}_{t+1}=A \alpha a k_{t}+Q \equiv \widehat{\kappa}\left(k_{t}\right),
$$

while capital accumulation in a corrupt environment is given by

$$
\widetilde{k}_{t+1}=A \alpha a k_{t}+Q-\nu_{c} N \beta\left(B^{*}\right)-e \equiv \widetilde{\kappa}\left(k_{t}\right),
$$

where $Q=M\left(\mu_{l} q_{l}+\mu_{m} q_{m}+\mu_{h} q_{h}\right)$. Appropriate parameter restrictions ensure that each of these transition paths displays a unique, stable steady state equilibrium at some positive level of capital. This stationary point is defined by $\widehat{k}=\widehat{\kappa}(\widehat{k})$ in the case of $(16)$ and by $\widetilde{k}=\widetilde{\kappa}(\widetilde{k})$ in the case of $(17){ }^{25}$ It is evident that, for any given $k_{t}, \widetilde{\kappa}(\cdot)<\widehat{\kappa}(\cdot)$. As such, $\widetilde{k}<\widehat{k}$ as well. These results show the negative effect of corruption on growth and development. The size of this effect depends on the amount by which resources are used up in the concealment and detection of corrupt behaviour (captured by the terms $\nu_{c} N \beta(\cdot)$ and $e$, respectively, in (17)).

As indicated above, our model predicts that corruption not only influences, but is also influenced by, economic development. To see this, use the expression for $w_{m t}$ in (7) to write the condition in (9) as

$$
k_{t} \leq \frac{p\left(B^{*}-\beta\left(B^{*}\right)\right)}{(1-p) \alpha A a_{m}\left(\mu_{m} M\right)^{\alpha-1}} \equiv \bar{k}
$$

Accordingly, there is a critical level of capital, $\bar{k}$, below which corruption exists and above which corruption is absent. This is due to the fact that higher levels of capital, associated with higher wages of all agents, imply

\footnotetext{
${ }^{25}$ The parameter restrictions are $A \alpha a \in(0,1)$ (ensuring uniqueness and stability in both cases) and $Q-\nu_{c} N \beta(\cdot)-e>0$ (ensuring non-degeneracy in both cases). The steady state levels of capital are $\widehat{k}=\frac{Q}{1-A \alpha a}$ and $\widetilde{k}=\frac{Q-\nu_{c} N \beta(\cdot)-e}{1-A \alpha a}$.
} 
higher costs to bureaucrats if they are caught being corrupt. At sufficently large values of $k_{t}$, these costs are prohibitive and the incentive to be corrupt disappears.

Given the above, we present Figure 2 as a complete characterisation of the economy's dynamic general equilibrium. Assuming that $\bar{k}<\widehat{k}$ (otherwise the analysis is trivial), one may distinguish between two types of development regime: the first - a low development regime (for which $k_{t}<\bar{k}$ ) - is characterised by relatively low levels of economic activity, accompanied by relatively high levels of corruption and inequality; the second - a high development regime (for which $k_{t}>\bar{k}$ ) - is characterised by relatively high levels of economic activity, accompanied by relatively low levels of corruption and inequality. The overall evolution of the economy depends essentially on the relationship between $\bar{k}$ and $\widetilde{k}$, together with $k_{0}$ (the initial stock of capital). Suppose that $k_{0}<\bar{k}<\widetilde{k}$. In this case the economy starts off in a situation where all corruptible bureacrats are corrupt and development takes place along the low capital accumulation path, $\widetilde{\kappa}(\cdot)$. The existence of widespread corruption impedes the effectiveness of public policy in redistributing wealth so that the degree of income inequality remains relatively high. At some point in time, $k_{t}$ reaches $\bar{k}$ and the incentive for each corruptible bureaucrat to continue being corrupt disappears. This propels the economy onto the high capital accumulation path, $\widehat{\kappa}(\cdot)$, after which it converges to the high steady state equilibrium, $\widehat{k}$. With corruption now absent, redistributive policy works more effectively, leading to a more equal income distribution. This chain of events describes a process of transition from the low development regime to the high development regime. But there is nothing in the model to guarantee such an outcome. To be sure, suppose that $k_{0}<\widetilde{k}<\bar{k}$. Under such circumstances, the economy is destined for the low steady state equilibrium, $\widetilde{k}$, being locked forever on the low capital accumulation path, $\widetilde{\kappa}(\cdot)$, and being mired forever with widespread corruption that fosters inequalities. To the extent that the high steady state equilibrium, $\widehat{k}$, would be attained if $k_{0}>\bar{k}$, the model now presents a situation in which limiting outcomes depend fundamentally on initial conditions.

The existence of mutliple long-run equlilbria means that countries with essentially the same structural characteristics, but different initial conditions, may face very different prospects in terms of their economic development and quality of governance. In terms of the above, these prospects would look decidedly bleak for countries located below the threshold point $\bar{k}$, unless there was the possibility of a fundamental adjustment that could produce a sudden turn of events. One such possibility is a windfall increase in the stock of capital that might allow the threshold to be breached. Another is a change 
in the value of some key structural parameter that may cause a favourable shift in the transition function and the threshold, itself. Yet even allowing for these events, it may still be difficult for some countries to escape from their predicament: switching from a state of low development to a state of high development is a prospect that is more within the reach of those economies located relatively close to the threshold than those that lie relatively far away from it. In addition, if countries do not share the same structural characteristics, then there would be a distribution of transition paths and a distribution of limiting outcomes that would reflect similar divisions between poor and rich countries. These observations suggest that cross-country differences in development, inequality and corruption may be persistent, rather than transitory, fixtures of the global economy.

\section{Conclusions}

Corruption may be difficult to define and measure precisely, but there is no doubt that it exists and no question that it has harmful effects. The fact that the most corrupt countries in the world tend also to display the most poverty and inequality is more than just a coincidence. Corruption can cause both a wastage and a misallocation of resources that work against efficiency and equality. In doing so, it can sabotage the prospects for growth and widen the gap between the rich and the poor. At the same time, corruption tends to flourish in less developed societies, where institutional structures are fragile and the returns to legitimate economic activity are small. Under such circumstances, the incentives that drive corrupt behaviour are often strong and cohesive, while the forces that oppose it are usually weak and fragmented. These observations are not new, but they have only recently become the subject of systematic formal investigation by economists. Our intention in this paper has been to take a further step in the same direction.

Our analysis has focused on corruption in public policy which is generally seen as one of the major causes of inequality and underdevelopment. Indeed, when such corruption exists, there may be a world of difference between what policies are intended by a government and what policies are actually implemented. The latter may have much less to do with the promotion of growth and reduction of poverty, and much more to do with the personal enrichment of a privelaged few pursuing their own hidden agenda. Bribery, fraud and theft on the part of policy administrators may not only interfere with development objectives, but may also undermine plans for redistribution. While the effects may be widespread throughout society, it is the poor who suffer the most: it is the poor who are hit hardest by economic decline 
and stagnation, who are least able to give kickbacks for services to which they are entitled and who are most reliant on social programmes that may be jeopardised by misgovernance.

For simplicity, we have confined our analysis to the case in which redistribution takes place through a system of direct transfers in the form of taxes and subsidies. In principle the analysis could be extended to incorporate other instruments of public policy that serve to alleviate poverty. Not least of these are public goods and services designed to benefit low-income households. Typical examples are publicly-funded programmes on education, training and health on which the poorest members of society rely the most. Such programmes can improve the economic circumstances of the poor by raising their human capital not only in terms of knowledge and expertise, but also in terms of health status and life expectancy. At the same time, both the quantity and quality of public services can suffer as a result of bureaucratic corruption for reasons alluded to earlier. We may capture these ideas in a simple and tractable way by allowing the productivities of households in different income classes (the parameters $a_{i}$ ) to depend more or less strongly on the provision of public goods which lies in the hands of bureaucrats. To the extent that such dependence decreases with the level of income, then any type of corrupt practice - be it tax evasion, job-shirking or theft - that reduces public goods provision will reduce the wages of the poor relative to the non-poor. This would reinforce our results by providing another mechanism through which corruption in public policy fosters inequality.

Another simplifying feature of our analysis is that the incidence of corruption emerges as a binary variable that takes on either a high value or a low value, depending on whether all corruptible bureaucrats are either corrupt or non-corrupt. An implication of this is that, if transition between development regimes takes place, then it does so abruptly (discontinuously) as soon as the threshold level, $\bar{k}$, is reached. As above, it is possible to extend the model to allow for smooth variations in the incidence of corruption along a continuous capital accumulation path. For example, if the costs of concealing illegal income (the function $\beta(\cdot)$ ) differed among bureacrats, then so too would the sizes of bribes and so too would the incentives to accept bribes. Under such circumstances, not all corrupt bureaucrats would cease being corrupt at the same time: only those for whom $p\left[B^{*}-\beta\left(B^{*}\right)\right]<(1-p) w_{m t}$ would do so. Ceteris paribus, as capital accumulation proceeds, this condition would become satisfied for a growing number of bureaucrats, implying a gradual decrease in corrupt activity. Depending on parameter values, the limiting outcome of the economy might be one in which this activity is at a mimimum, a maximum or somewhere in between.

The predictions of our analysis accord well with empirical evidence: cor- 
ruption is positively correlated with income inequality and negatively correlated with economic development. Moreover, we are able to explain how corruption and poverty may reinforce each other to become permanent characteristics of an economy. As stated at the beginning of this paper, the World Bank has singled out corruption as being a major obstacle to economic and social development. Our analysis may be seen as providing formal support for this view. 


\section{References}

[1] Acemoglou, D. and T. Verdier, 1998. Property rights, corruption and the allocation of talent: a general equilibrium approach. Economic Journal, 108, 1381-1403.

[2] Acemoglou, D. and T. Verdier, 2000. The choice between market failures and corruption. American Economic Review, 90, 194-211.

[3] Aghion, P and P. Bolton, 1997. A theory of trickle-down growth and development. Review of Economic Studies, 64, 151-172.

[4] Ahlin, C., 2001. Corruption: political determinants and macroeconomic effects. Working Paper No.01-W26, Department of Economics, Vanderbilt University.

[5] Alesina, A. and A. Drazen, 1991. Why are stabilisations delayed? American Economic Review, 81, 1170-1188.

[6] Alesina, A. and D. Rodrik, 1994. Distributive poilitics and economic growth. Quarterly Journal of Economics, 109, 465-490.

[7] Andvig, J.C. and K.O. Moene, 1990. How corruption may corrupt. Journal of Economic Behaviour and Organisations, 13, 63-76.

[8] Banerjee, A.V., 1997. A theory of misgovernance. Quarterly Journal of Economics, 112, 1289-1332.

[9] Banerjee, A.V. and A.F. Newman, 1993. Occupational choice and the process of development. Journal of Political Economy, 101, 274-298.

[10] Bardhan, P., 1997. Corruption and development: a review of issues. Journal of Economic Literature, 35, 1320-1346.

[11] Besley, T. and J. McLaren, 1993. Taxes and bribery: the role of wage incentives. Economic Journal, 108, 119-141.

[12] Blackburn, K. and N. Bose, 2003. A model of trickle-down through learning. Journal of Economic Dynamics and Control, 27, 445-466.

[13] Cadot, O., 1987. Corruption as a gamble. Journal of Public Economics, $33,223-244$.

[14] Carillo, J.D., 2000. Corruption in hierarchies. Annales d'Economie et de Statistique, 10, 37-61. 
[15] Chander, P. and L. Wilde, 1992. Corruption in tax administration. Journal of Public Economics, 49, 333-349.

[16] Ehrlich, I. and F.T. Lui, 1999. Bureaucratic corruption and endogenous economic growth. Journal of Political Economy, 107, 270-293.

[17] Foellmi, R. and M. Oechslin, 2003. Who gains from non-collusive corruption? Working Paper No.142, Insitute for Empirical Research in Economics, Zurich University.

[18] Galor, O. and J. Zeira, 1993. Income distribution and macroeconomics. Review of Economic Studies, 60, 35-52.

[19] Glaeser, E., J. Sheinkman and A. Schleifer, 2002. The injustice of inequality. Working Paper No.9150, National Bureau of Economic and Social Research.

[20] Gupta, S., H. Davoodi and R. Alonso-Terme, 2002. Does corruption affect income inequality and poverty? Economics of Governance, 3, 2345.

[21] Gyimah-Brempong, K., 2002. Corruption, economic growth and income inequality in Africa. Economics of Governance, 3, 183-209.

[22] Huntington, S.P., 1968. Political Order in Changing Societies. Yale University Press, New Haven.

[23] Jain, A.K. (ed.), 1998. The Economics of Corruption. Kluwer Academic Publishers, Massachusettes.

[24] Jain, A.K., 2001. Corruption: a review. Journal of Economic Surveys, $15,71-121$.

[25] Klitgaard, R., 1988. Controlling Corruption. University of California Press, Berkeley.

[26] Klitgaard, R., 1990. Tropical Gangsters. Basic Books, New York.

[27] Leff, N.H., 1964. Economic development through bureaucratic corruption. American Behavioural Scientist, 8, 8-14.

[28] Leys, C., 1970. What is the problem about corruption? In A.J. Heidenheimer (ed.), Political Corruption: Readings in Comparative Analysis, Holt Reinehart, New York. 
[29] Li, H., L.C. Xu and H. Zou, 2000. Corruption, income distribution and growth. Economics and Politics, 12, 155-182.

[30] Lui, F., 1985. An equilibrium queuing model of corruption. Journal of Political Economy, 93, 760-781.

[31] Mauro, P., 1995. Corruption and growth. Quarterly Journal of Economics, 110, 681-712.

[32] Mauro, P., 1997. The effects of corruption on growth, invsetment and government expenditure: a cross-country analysis. In K.A. Elliott (ed.), Corruption and the Global Economy, Institute for International Economics, Washington D.C.

[33] Mookherjee, D. and I.P.L. Png, 1995. Corruptible law enforcers: how should they be compensated? Economic Journal, 105, 145-159.

[34] Perotti, R., 1993. Political equilibrium, income distribution and growth. Review of Economic Studies, 60, 755-776.

[35] Persson, T. and G. Tabellini, 1994. Is inequality harmful for growth? American Economic Review, 84, 600-621.

[36] Ravallion, M. and S. Chen, 1997. What can new survey data tell us about recent changes in distribution and poverty? World Bank Economic Review, 11, 357-382.

[37] Rose-Ackerman, S., 1975. The economics of corruption. Journal of Public Economics, 4, 187-203.

[38] Rose-Ackerman, S., 1978. Corruption: A Study in Political Economy. Academic Press.

[39] Rose-Ackerman, S., 1999. Corruption and Government: Causes, Consequences and Reform. Cambridge University Press, Cambridge.

[40] Sarte, P.-D., 2000. Informality and rent-seeking bureaucracies in a model of long-run growth. Journal of Monetary Economics, 46, 173-197.

[41] Shleifer, A. and R. Vishny, 1993. Corruption. Quarterly Journal of Economics, 108, 599-617.

[42] Tanzi, V., 1998. Corruption around the world: causes, scope and cures. IMF Working Paper No.98/63. 
[43] Tanzi, V. and H. Davoodi, 1997. Corruption, public investment and growth. IMF Working Paper No.WP/97/139.

[44] Treisman, D., 2000. The causes of corruption: a cross-national study. Journal of Public Economics, 76, 399-457.

[45] United Nations, 1989. Corruption in Government. United Nations, New York.

[46] Wei, S., 2000. How taxing is corruption on international investors? Review of Economics and Statistics, 82, 1-11.

[47] World Bank, 1990. World Development Report, 1990. Oxford University Press, New York.

[48] World Bank, 1991. World Development Report, 1990. Oxford University Press, New York.

[49] World Bank, 2002. Voices of the Firms 2000: Investment Climate and Governance Findings of the World Business Environment Survey (WBES). World Bank, Washington D.C. 
Figure 1

Income Distribution in

Corrupt and Non-corrupt Environments

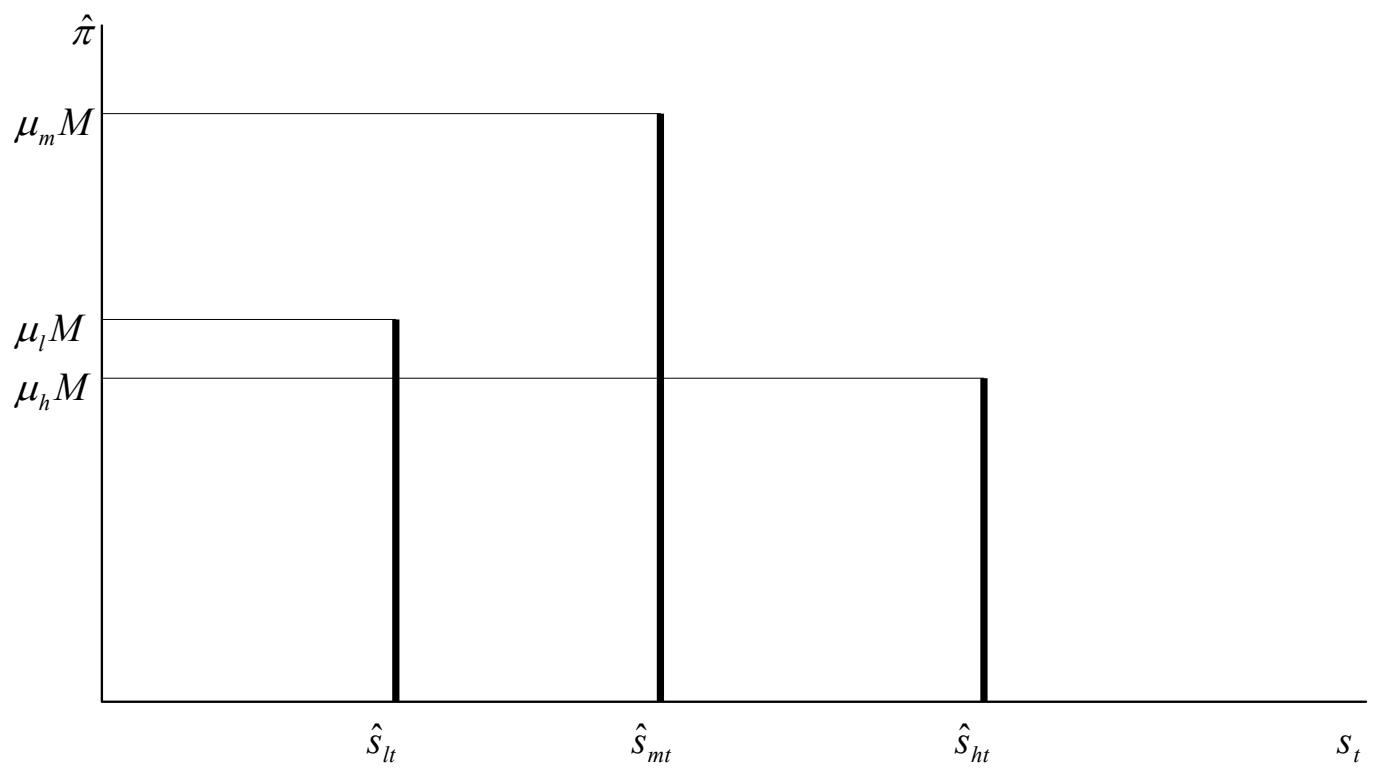

A. Non-corruption

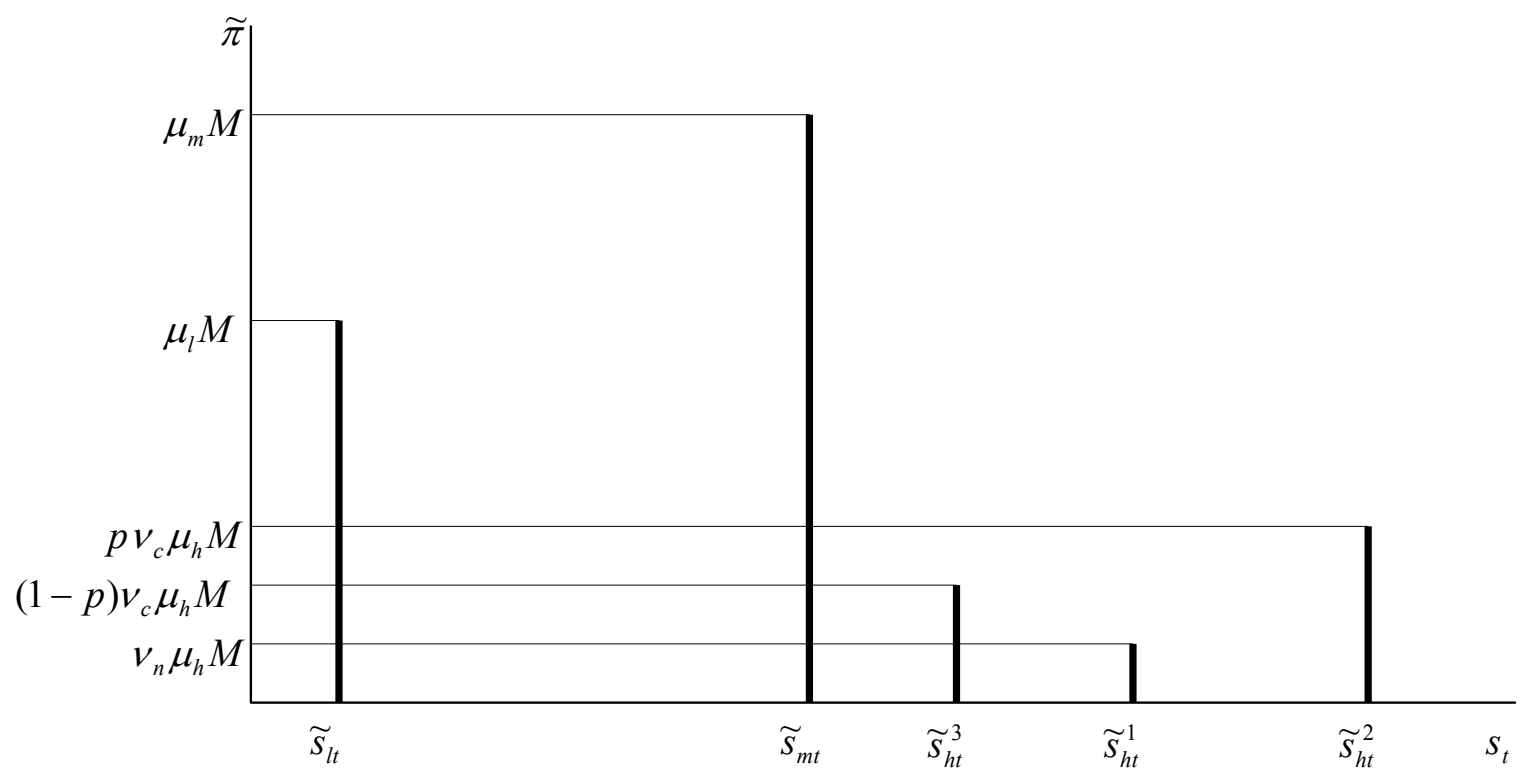

B. Corruption 
Figure 2

General Equilibrium

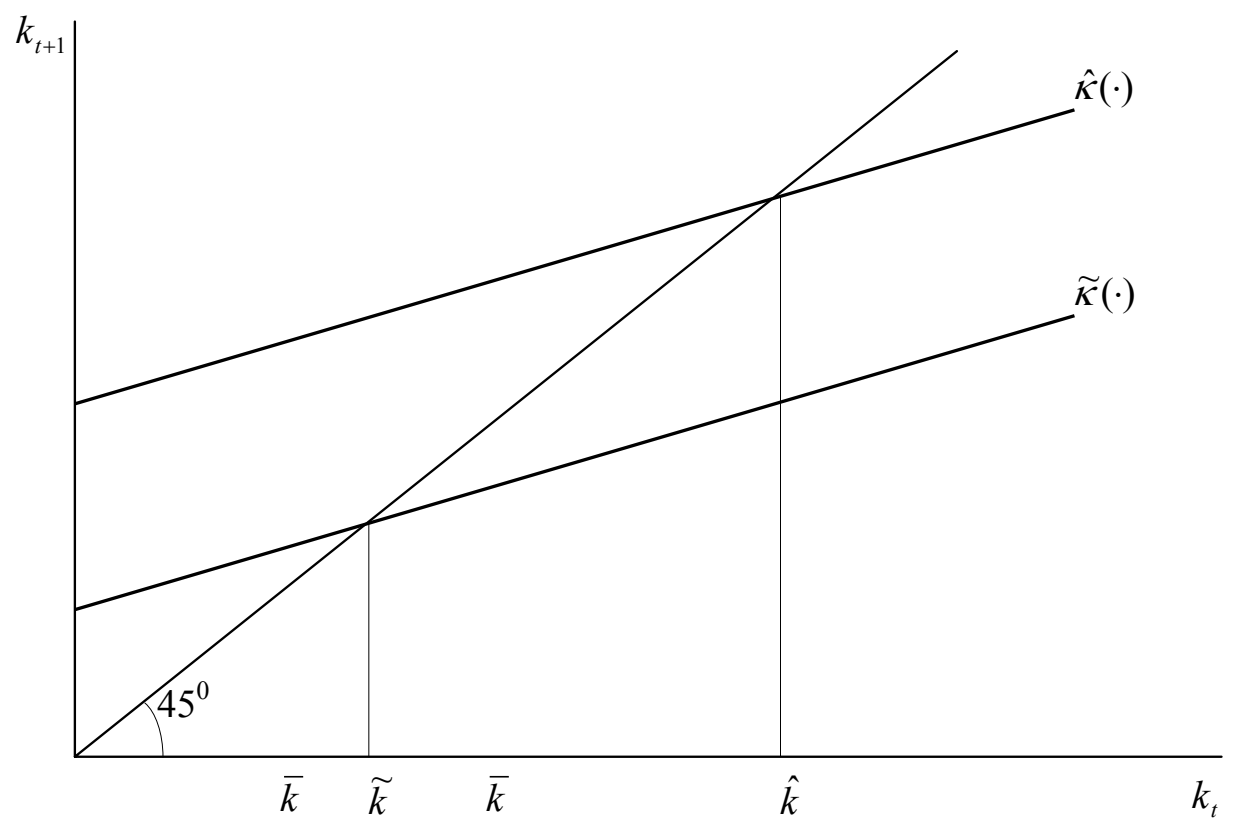

A. Capital accumulation

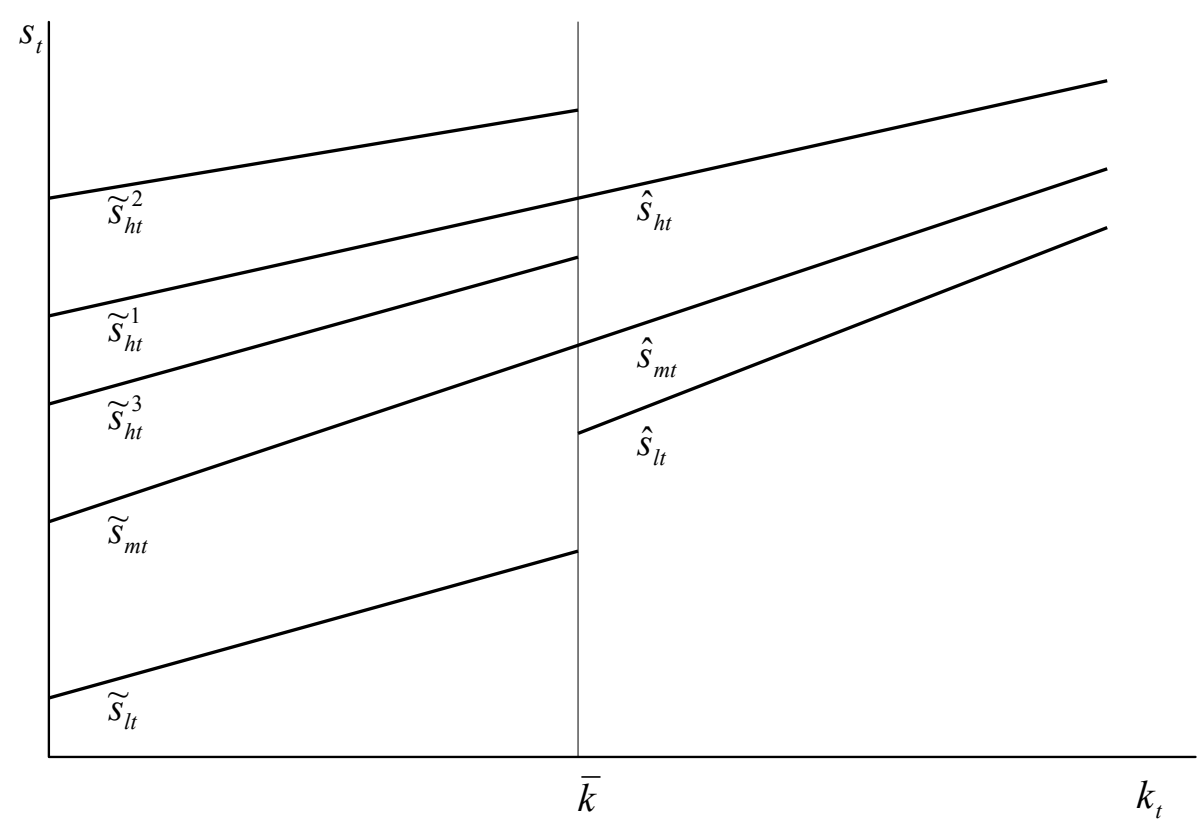

B. Incomes 